\title{
CRYSTAL-CHEMICAL CHANGES OF MIXED-LAYER KAOLINITE-SMECTITE WITH PROGRESSIVE KAOLINIZATION, AS INVESTIGATED BY TEM-AEM AND HRTEM
}

\author{
Javier Cuadros $^{1}{ }^{*}$, Fernando Nieto ${ }^{2}$, and Teresa Wing-Dudek ${ }^{1}$ \\ ${ }^{1}$ Department of Mineralogy, Natural History Museum, Cromwell Road, London SW7 5BD, UK \\ 2 Departamento de Mineralogía y Petrología and IACT, Universidad de Granada-CSIC, 18002 Granada, Spain
}

\begin{abstract}
The mechanism for the kaolinization of smectite is extremely complex. The purpose of this study was to explore this mechanism by providing more microscopic information about kaolinite-smectite (K-S) intermediate phases. Crystal-chemical changes were investigated and integrated in a model of the transformation mechanism. Eight K-S samples from three localities, derived from volcanic ash beds, were studied using transmission and analytical electron microscopy (TEM, AEM) and high-resolution TEM (HRTEM). The study completes a previous investigation, using several analytical techniques. The samples cover the range of K-S composition available from the previously studied sample set. Analysis by TEM indicated the preservation of particle morphology throughout the process. Most K-S particles had anhedral, smectite-like morphology, and only the most kaolinitic specimen revealed the coexistence of anhedral and euhedral, hexagonal particles. Analytical electron microscopy showed large chemical variations within samples, corresponding to various degrees of smectite kaolinization. Comparison of chemical results (Si/Al) and $d_{060}$ values (proxy for octahedral composition) with the extent of kaolinization from thermogravimetry (TG) indicates that chemical changes in the octahedral sheet occur mainly when the proportion of kaolinite is $40-70 \%$. The results above are consistent with kaolinization occurring via layerby-layer transformation through the progressive loss of individual tetrahedral sheets in smectite layers and subsequent chemical changes in the octahedral sheet. Such a mechanism would produce the results observed in this study: (1) most particles preserve their original morphology; (2) significant variation in terms of the extent of transformation of particles within samples, and (3) formation of crystal structures intermediate between those of smectite and kaolinite, with parts of the tetrahedral sheets missing (kaolinite-like patches). Such structures become least stable at kaolinite $\sim 50 \%$, when the perimeter of the kaolinite-like patches is largest and chemical changes in the octahedral sheet can occur more easily. Kaolinite layers could not be resolved by HRTEM in most cases and showed lattice fringes corresponding to superstructures. A model was established to quantify kaolinite and smectite layers in the HRTEM images with results which matched TG-derived values.
\end{abstract}

Key Words-HRTEM, Kaolinite-smectite, Solid-state Transformation, TEM-AEM.

\section{INTRODUCTION}

A recent study of the mechanism of smectite kaolinization via mixed-layer kaolinite-smectite (K-S) used a multi-analytical approach (Dudek et al., 2006, 2007; Cuadros and Dudek, 2006; Cuadros and WingDudek, 2007) and showed that the transformation mechanism is complex and that structural and chemical changes occur sequentially. Initially, parts of the tetrahedral sheets of smectite layers are lost, creating what was referred to as "kaolinite-like patches," i.e. parts of the smectite layers where one of the tetrahedral sheets is missing, hydroxyl groups replace oxide ions in the vertices of the exposed octahedra, but no further chemical or structural change occur. As the loss of tetrahedra proceeds, the remaining tetrahedral sheets and the octahedral sheets experience the chemical changes leading to a real kaolinite structure. The result of such a

\footnotetext{
* E-mail address of corresponding author: j.cuadros@nhm.ac.uk DOI: $10.1346 / C C M N .2009 .0570607$
}

process is a very complex intermediate structure that, presumably, is much less stable than the smectite or kaolinite end-members. The mechanism also results in a complex analytical signature of K-S where several techniques are necessary in order to obtain an accurate picture of K-S crystal chemistry. Amouric and Olives (1998) provided HRTEM evidence for the occurrence of such a transformation mechanism, though they also observed kaolinite layers intercalated between two smectite layers as if the TO layer was crystallizing in the interlayer space of smectite. Ryan and Huertas (2009) also found the mechanism of tetrahedra stripping, as well as a combination of (1) inclusion of Alhydroxide in the interlayer, and (2) tetrahedral inversion. Their study of pedogenic Fe-rich K-S from a moist tropical climate includes a variety of analytical techniques which produced results in agreement with those of Dudek et al. (2006, 2007), Cuadros and Dudek (2006), and Cuadros and Wing-Dudek (2007).

Analytical results (TEM analysis) of K-S are presented which complement previous work (Dudek et al., 2006, 2007; Cuadros and Dudek, 2006; Cuadros and Wing-Dudek, 2007). The TEM investigation shows a 
new aspect of this very complex transformation, in which the chemical evolution of individual particles is very heterogeneous. The study confirms the K-S transformation model by showing that most of the chemical changes occur at the stage when $\sim 50 \%$ of the structure corresponds to kaolinite-like patches, precisely the stage at which the crystal lattice is most unstable and the energy barrier for chemical changes is lowest.

\section{MATERIALS AND METHODS}

Eight K-S samples were analyzed (Table 1) - their origins were described by Dudek et al. (2006) and Cuadros and Dudek (2006) and a full mineralogical and chemical characterization was recorded by Dudek et al. (2006). The nature of the kaolinitic layers during much of the transformation sequence cannot be defined absolutely (Dudek et al., 2006) because the layers could also be defined as halloysite. However, the transformation end-member is kaolinite, for which reason this term is preferred. The samples studied cover the whole range of kaolinite composition as measured by XRD. However, thermogravimetric analysis (TG) yields different kaolinite contents due to the complex structure of K-S (Dudek et al., 2006). To determine the kaolinite content $(\% \mathrm{~K})$ from $\mathrm{TG}$ values, the wt.\% loss in the dehydroxylation of K-S was transformed into $\% \mathrm{~K}$ using the regression line in figure 8 of Dudek et al. (2006). The regression line averages the progress of increasing weight loss of K-S samples with increasing kaolinite content. Using this line has the advantage of decreasing the analytical error of the individual measurements and thus provides a more accurate value for $\% \mathrm{~K}$. The $\% \mathrm{~K}$ (HRTEM) values in Table 1 are from the present study and are described below.

\section{TEM-AEM analysis}

The samples' particle morphology was examined using TEM, and quantitative chemical analyses were obtained by AEM in the same transmission mode. The microscope used was a Philips CM20 (STEM, at the
C.I.C., University of Granada), with an EDAX solidstate EDX detector, operating at $200 \mathrm{kV}$. Analyses were obtained from powdered portions deposited on a holey $\mathrm{C}$-coated $\mathrm{Au}$ grid. This mode of preparation disperses individual grains of minerals onto the grid surface. Albite, biotite, spessartine, muscovite, olivine, and titanite standards were used to obtain $\mathrm{K}$-factors for the transformation of intensity ratios to concentration ratios following Cliff and Lorimer (1975). The structural formulae of K-S were calculated on the basis of 22 negative charges, i.e. $\mathrm{O}_{10}(\mathrm{OH})_{2}$, independently of the true nature of the particle.

Alkali loss is a significant problem in the TEM analysis of clay minerals (Van Der Pluijm et al., 1988). The effect increases as the analysis area becomes smaller and the material less crystalline. In some extreme cases other elements such as $\mathrm{Mg}$ or Al may also be affected. A comparison of analyses obtained for 15 and $100 \mathrm{~s}$ was used, therefore, to check for this effect, as shorter counting times are usually employed, as a compromise, for major-alkali analyses (Nieto et al., 1996). Preliminary analyses of these K-S samples showed them to be affected by volatilization of Al. The possibility of obtaining analyses of very small areas on the high-resolution images was discarded, therefore, and a special routine, based on scanning the electron beam over a large window covering the entire particle to be analyzed, was used. In such conditions the differences in the $\mathrm{Al} / \mathrm{Si}$ ratios obtained in the short- and long-period alternatives was minimal, and so the $100 \mathrm{~s}$ spectrum was deployed to measure all of the elements.

\section{HRTEM analysis}

Five samples were analyzed in HRTEM mode to investigate the evolution of the mixed-layer structures. The samples were chosen according to their $\% \mathrm{~K}$ content as measured by XRD, and with a sufficient kaolinite content to facilitate the observation of kaolinite layers (one sample with no kaolinite, two with intermediate kaolinite content, and two with the greatest kaolinite content; Table 1). They were first prepared as oriented mounts on glass slides. A small amount of the sample

Table 1. Samples studied, their sources, percentage of kaolinite in K-S as determined by XRD, TG (previous study), and HRTEM, and the techniques used in the present study.

\begin{tabular}{llccc}
\hline Sample & \multicolumn{1}{c}{ Locality } & $\begin{array}{c}\% \mathrm{~K} \\
(\mathrm{XRD})\end{array}$ & $\begin{array}{c}\% \mathrm{~K} \\
(\mathrm{TG})\end{array}$ & $\begin{array}{c}\text { Present study } \\
(\mathrm{HRTEM})\end{array}$ \\
\hline TR-4 & Los Trancos, Spain & 0 & 15 & HRTEM \\
LT-9/1 & Los Trancos, Spain & 16 & 36 & TEM-AEM \\
TR-119 & Los Trancos, Spain & 32 & 43 & TEM-AEM \\
T-18 & Los Trancos, Spain & 37 & 44 & TEM-AEM \\
TR-121 & Los Trancos, Spain & 49 & 48 & TEM-AEM HRTEM \\
LT-2 & Los Trancos, Spain & 55 & 49 & TEM-AEM HRTEM \\
RS49 & Yucatan, Mexico & 80 & 60 & TEM-AEM HRTEM \\
CWP-73 & Northamptonshire, England & 85 & 65 & HRTEM
\end{tabular}


was extracted from the glass slide and embedded in resin according to a procedure based on the technique of Spurr (1969), adapted by Tessier (1984) and Elsass et al. (1998). The small piece of oriented K-S from the glass slide was coated with $2 \%$ agar and dehydrated by methanol-for-water exchange. Methanol was replaced, in a step-like manner, by propylene oxide (1,2-epoxypropane), and finally the sample was impregnated with the low-viscosity epoxy resin of Spurr (1969). The sample was then sliced into ultrathin sections with a diamond knife (LKB ultramicrotome), and the sections $(<50 \mathrm{~nm}$ thick) were deposited on $\mathrm{C}$-coated $\mathrm{Cu}$ grids.

\section{RESULTS}

\section{Chemical composition of $K-S$}

As AEM is not an absolute-composition technique, only ratios between the various elements can be measured and the compositions need to be normalized in some way, usually on the basis of the mineral formulae. For the sake of simplicity, the analyses of the K-S individual particles (Table 2) are presented normal- ized to a smectite composition, whether or not they are true smectite. Some particles of the less kaolinitic samples have compositions that match that of smectite, and they are marked ' $\mathrm{S}$ ' in Table 2. The compositions are highly variable from particle to particle within samples, however. The conditions used to label analyses as corresponding to smectite were: (1) $4>\mathrm{Si}>3.75$, and (2) a good charge balance.

The compositions of the various grains of each sample tend toward a positive correlation of the $\mathrm{Mg} / \mathrm{Al}$ and $\mathrm{Si} / \mathrm{Al}$ ratios, which is consistent with various proportions of smectite and kaolinite (Figure 1). Such a correlation is particularly evident for sample T-18, which shows the broadest range of compositions and points clearly to the end-member kaolinite composition of $\mathrm{Si}_{2} \mathrm{Al}_{2} \mathrm{Mg}_{0}$. The different positions and slopes of the various lines defining the relationships between $\mathrm{Mg} / \mathrm{Al}$ and $\mathrm{Si} / \mathrm{Al}$ ratios (Figure 1) are a consequence of several factors: (1) different chemical compositions of the smectitic component of the various samples; (2) analytical inaccuracy, as $\mathrm{Mg}$ is a minor component (Table 2); and (3) heterogeneous chemical changes in the kaolini-

Table 2. Representative chemical compositions of K-S particles. Some of the less kaolinitic particles have compositions that match that of smectite. The other analyses have also been normalized to smectite for comparative purposes.

\begin{tabular}{|c|c|c|c|c|c|c|c|c|c|c|c|}
\hline Sample & $\begin{array}{l}\text { Analysis } \\
\text { number }\end{array}$ & $\begin{array}{c}\text { Smectite } \\
\text { composition }\end{array}$ & $\mathrm{Si}$ & ${ }^{\mathrm{IV}} \mathrm{Al}$ & ${ }^{\mathrm{VI}} \mathrm{Al}$ & $\mathrm{Mg}$ & $\mathrm{Fe}$ & Eoct & $\mathrm{K}$ & $\mathrm{Ca}$ & Int ch \\
\hline \multirow{4}{*}{ LT-9/1 } & 1 & $\mathrm{~S}$ & 3.85 & 0.15 & 1.62 & 0.31 & 0.09 & 2.02 & 0.00 & 0.21 & 0.41 \\
\hline & 2 & $\mathrm{~S}$ & 3.82 & 0.18 & 1.56 & 0.35 & 0.10 & 2.01 & 0.03 & 0.22 & 0.48 \\
\hline & 6 & $\mathrm{~S}$ & 3.87 & 0.13 & 1.53 & 0.40 & 0.07 & 2.00 & 0.03 & 0.24 & 0.52 \\
\hline & 8 & & 4.02 & 0.00 & 1.59 & 0.34 & 0.10 & 2.03 & 0.00 & 0.14 & 0.28 \\
\hline \multirow{4}{*}{ TR-119 } & 1 & $\mathrm{~S}$ & 3.76 & 0.24 & 1.63 & 0.31 & 0.12 & 2.06 & 0.02 & 0.17 & 0.36 \\
\hline & 4 & $\mathrm{~S}$ & 3.98 & 0.02 & 1.85 & 0.09 & 0.07 & 2.00 & 0.03 & 0.03 & 0.10 \\
\hline & 7 & S & 3.98 & 0.02 & 1.67 & 0.22 & 0.10 & 1.99 & 0.02 & 0.12 & 0.26 \\
\hline & 15 & $\mathrm{~S}$ & 4.00 & 0.00 & 1.75 & 0.21 & 0.07 & 2.02 & 0.00 & 0.07 & 0.14 \\
\hline \multirow{5}{*}{$\mathrm{T}-18$} & 2 & S & 3.89 & 0.11 & 1.38 & 0.52 & 0.17 & 2.07 & 0.07 & 0.17 & 0.42 \\
\hline & 7 & & 3.34 & 0.66 & 1.91 & 0.10 & 0.14 & 2.15 & 0.00 & 0.16 & 0.31 \\
\hline & 8 & & 3.64 & 0.36 & 1.66 & 0.26 & 0.16 & 2.07 & 0.00 & 0.21 & 0.41 \\
\hline & 13 & & 3.27 & 0.73 & 1.84 & 0.17 & 0.19 & 2.20 & 0.02 & 0.14 & 0.29 \\
\hline & 14 & & 3.68 & 0.32 & 1.60 & 0.36 & 0.10 & 2.07 & 0.09 & 0.19 & 0.47 \\
\hline \multirow{5}{*}{ TR-121 } & 1 & & 3.72 & 0.28 & 1.64 & 0.33 & 0.16 & 2.13 & 0.05 & 0.09 & 0.23 \\
\hline & 2 & & 3.62 & 0.38 & 1.69 & 0.24 & 0.17 & 2.11 & 0.02 & 0.14 & 0.29 \\
\hline & 3 & & 3.64 & 0.36 & 1.73 & 0.21 & 0.14 & 2.07 & 0.00 & 0.17 & 0.35 \\
\hline & 6 & & 3.72 & 0.28 & 1.83 & 0.12 & 0.09 & 2.04 & 0.02 & 0.14 & 0.29 \\
\hline & 7 & & 4.03 & 0.00 & 1.69 & 0.21 & 0.12 & 2.01 & 0.02 & 0.10 & 0.22 \\
\hline \multirow{4}{*}{ LT-2 } & 2 & & 3.58 & 0.42 & 1.87 & 0.14 & 0.09 & 2.10 & 0.02 & 0.12 & 0.26 \\
\hline & 7 & $\mathrm{~S}$ & 3.96 & 0.04 & 1.74 & 0.22 & 0.07 & 2.03 & 0.00 & 0.09 & 0.17 \\
\hline & 13 & & 3.55 & 0.45 & 1.64 & 0.24 & 0.17 & 2.05 & 0.02 & 0.26 & 0.54 \\
\hline & 16 & & 3.63 & 0.37 & 1.69 & 0.28 & 0.12 & 2.09 & 0.02 & 0.17 & 0.36 \\
\hline \multirow{4}{*}{ RS49 } & 6 & & 3.64 & 0.36 & 1.85 & 0.17 & 0.15 & 2.18 & 0.00 & 0.00 & 0.00 \\
\hline & 7 & & 3.60 & 0.40 & 1.93 & 0.05 & 0.14 & 2.12 & 0.03 & 0.03 & 0.10 \\
\hline & 8 & & 4.01 & 0.00 & 1.78 & 0.12 & 0.10 & 2.00 & 0.07 & 0.03 & 0.14 \\
\hline & 17 & & 3.38 & 0.62 & 2.10 & 0.09 & 0.05 & 2.24 & 0.00 & 0.00 & 0.00 \\
\hline
\end{tabular}




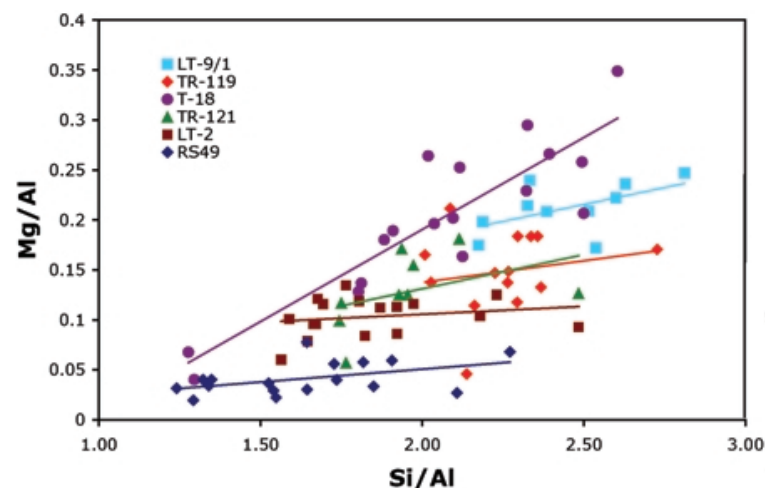

Figure 1. $\mathrm{Mg} / \mathrm{Al}$ vs. Si/Al ratios from AEM. The lines are best fits of the values corresponding to different particles for each sample.
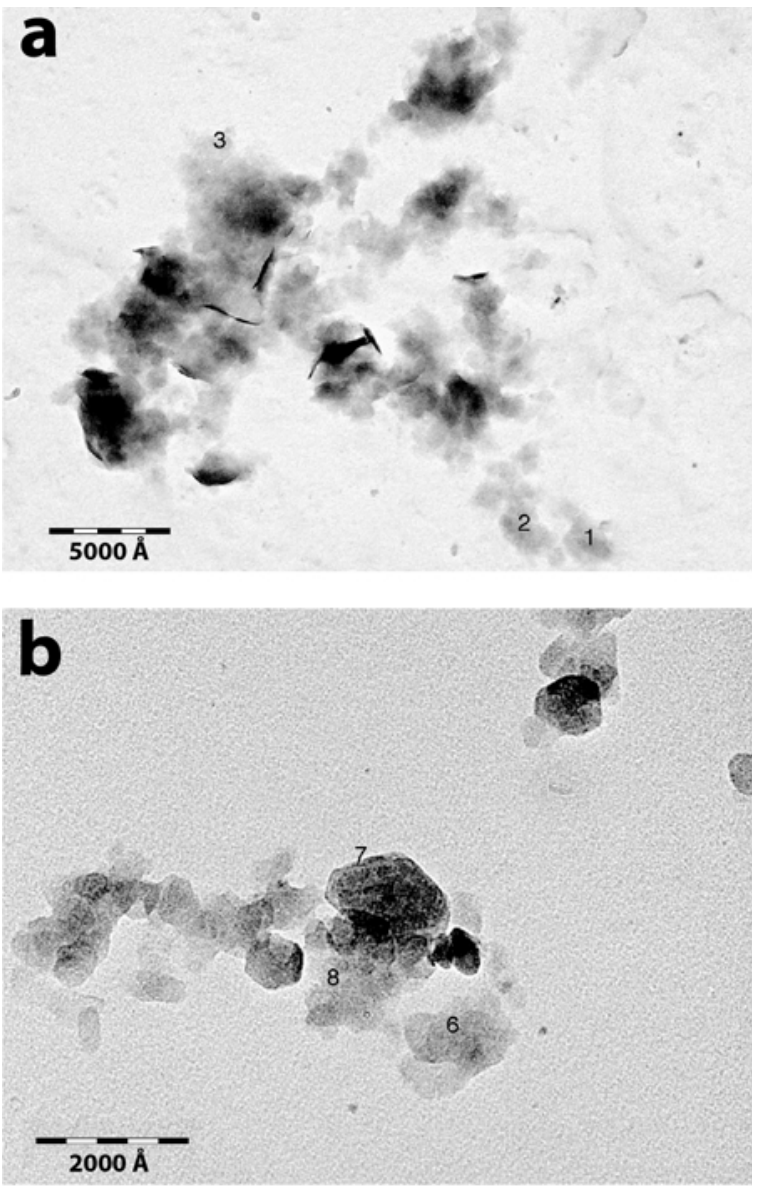

Figure 2. TEM images showing the morphology of the K-S particles in samples TR-121 (a) and RS49 (b). Irregular, anhedral morphology, typical of smectite, is only present in less kaolinitic samples, but coexists with hexagonal particles in the most kaolinitic sample. Numbers refer to the analyses listed in Table 2 . zation process. In any case, the trend in all samples is broadly toward a kaolinitic composition. Similar tendencies are also found for ratios of other elements such as $\mathrm{Ca} / \mathrm{Al}$ vs. $\mathrm{Si} / \mathrm{Al}$ (not shown). The variety of the compositions of the various grains within samples, therefore, represents different proportions of smectite and kaolinite, i.e. different degrees of transformation.

Most of the particles analyzed showed irregular, anhedral morphology, typical of smectite. However, in the most kaolinitic sample, RS-49, hexagonal morphologies are common and coexist with anhedral particles (Figure 2b). All other samples display only anhedral particle morphology (Figure 2a). All the observed hexagonal particles have Al-rich compositions, but the opposite is not true; anhedral particles may have either Al-poor (e.g. analysis no. 8, Figure $2 \mathrm{~b}$ and Table 2) or Al-rich (e.g. analysis no. 6, Figure $2 \mathrm{~b}$ and Table 2) compositions.

\section{Chemistry vs. kaolinite content}

In order to compare the progress of the chemical transformation of $\mathrm{K}-\mathrm{S}$ with kaolinite content, the $\mathrm{Si} / \mathrm{Al}$ ratio $v s . \% \mathrm{~K}$, as determined using both XRD (Figure $3 \mathrm{a}$ ) and TG (Figure 3b), was plotted. The open symbols correspond to AEM analyses of individual crystals. The bold symbols are from chemical analysis of macroscopic specimens, many of them by X-ray fluorescence (XRF),
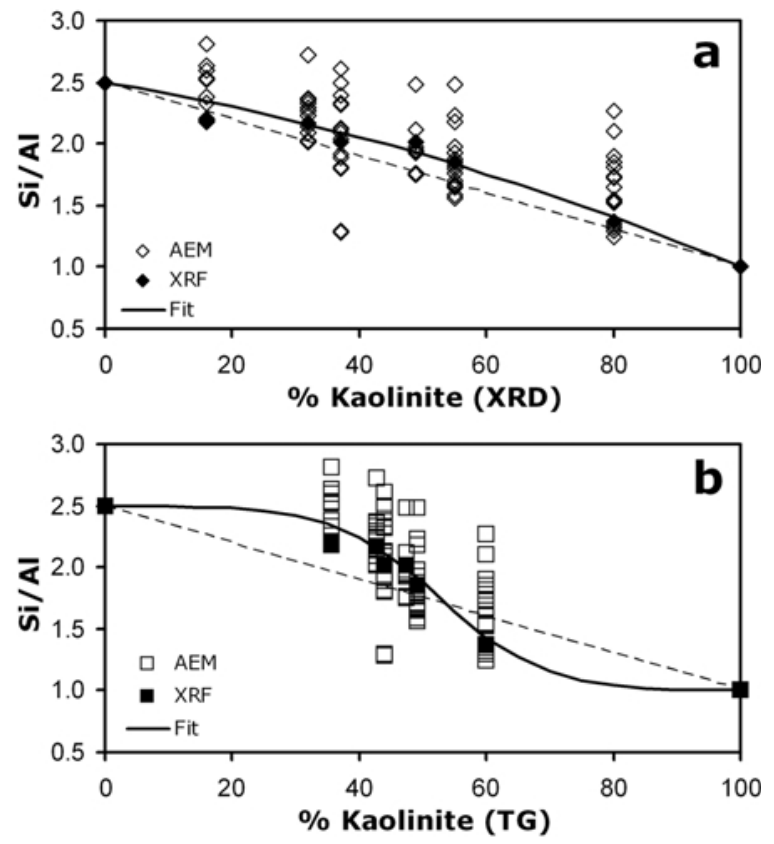

Figure 3. Si/Al ratio from AEM (open symbols) and XRF (filled symbols) vs. \% kaolinite, as determined using XRD (a) and TG (b). $\mathrm{The} \mathrm{Si} / \mathrm{Al}$ value for the kaolinite end-member is the ideal one. The solid lines are best fits of the XRF values: a first-order polynomial equation for XRD-derived $\% \mathrm{~K}$, and a logistic equation for TGderived $\% \mathrm{~K}$. The dashed line is a straight line connecting endmembers, for reference. 
and thus are an average for each sample (taken from Dudek et al., 2006). The standard deviation of the latter analyses is $1.15 \%$ of the measured value, which translates into \pm 0.013 in the plots. The full lines are regressions fitted to the XRF values. The $\mathrm{Si} / \mathrm{Al}$ ratio for kaolinite is the ideal one. The dotted line is a straight line linking the smectite and kaolinite end-members, for reference. If the kaolinization process occurred by means of smectite dissolution and precipitation of kaolinite, the data points would plot on this straight line because the chemical and structural changes would occur simultaneously. Although these data do not provide any kinetic information in terms of the absolute velocity of the transformation process, they indicate the relative timing between the chemical and structural changes. The AEM Si/Al ratios are quite varied, showing the great chemical heterogeneity of the individual crystals. Some of this heterogeneity is obviously due to the fact that the real kaolinite content in each crystal is different. The $\% \mathrm{~K}$ values in the figure are the average for macroscopic samples. Interestingly, the XRF values tend to fall in the lower range of the AEM ratios. The following possible reasons are suggested. When suspended in alcohol, the less kaolinitic crystals, containing fewer layers, were concentrated in the upper part of the suspension and were collected preferentially for the TEM study. Alternatively, when performing the analyses, the bias was toward analysis of thinner (i.e. less kaolinitic) crystals.

As discussed by Dudek et al. (2006), \%K values from TG are more accurate than those from XRD, because TG detects all areas where layers have lost part (or all) of one of the tetrahedral sheets, whereas XRD cannot detect small 'kaolinite-like patches or domains' because they do not allow layer collapse to $\sim 7 \AA$. Moreover, XRD does not detect part of the external area of the crystals because the inter-crystal contact is not perfectly parallel. For these reasons, $\% \mathrm{~K}(\mathrm{TG})$ is considered as the most accurate measurement of the progress of the kaolinization reaction from the structural point of view.

The XRF vs. \%K (XRD) data could be fitted with a second-order polynomial equation (Figure 3a). When compared with the straight dashed line, it shows that the chemical evolution of K-S is somewhat delayed with respect to the $\% \mathrm{~K}$ as measured by XRD. This is in agreement with the previous conclusion indicating that XRD and chemical changes do not occur simultaneously in the transformation. The shape of the curve from $\% \mathrm{~K}$ (TG) values is more complex (Figure $3 \mathrm{~b}$ ). The $\% \mathrm{~K}$ values concentrate toward the middle range and, as a result, the chemical changes are shown to concentrate in this region. This is a reasonable finding because it indicates that the chemical changes occur mainly while the structure of K-S is most unstable due to the loss of tetrahedra, and most 'open,' as the large kaolinite-like domains create voids that open to the interlayer space, facilitating ion diffusion. The steep change in $\mathrm{Si} / \mathrm{Al}$ cannot be due only to the loss of $\mathrm{Si}$ and corresponding relative increase in the proportion of $\mathrm{Al}$, as this change should progress exactly parallel to the removal of tetrahedra. Another cause for the increase in Al is the loss of $\mathrm{Mg}$ and $\mathrm{Fe}$ in the octahedral sheet, and the resultant $\mathrm{Al}$ enrichment. The chemical changes in the octahedral sheet were investigated further and will be discussed below.

\section{HRTEM}

Lattice-fringe HRTEM images are difficult to obtain from very hydrated and/or small-sized clay particles due to the structural damage caused by the electron beam. This is especially true for K-S materials (Amouric and Olives, 1998). In the present study, quick amorphization of areas showing lattice fringes was observed when the magnification was increased, consistent with the abovementioned Al loss during analyses. Images were captured (plates or digital), therefore, of areas that showed lattice fringes, without trying to increase the resolution and with minimum focusing. In such conditions the Scherzer focus cannot be guaranteed for all images and the lattice fringes may correspond either to individual layers or to superstructures containing a combination of two or more layers. Computer simulations by Guthrie and Veblen $(1989,1990)$ showed that the positions of light and dark fringes in mixed-layer minerals depend on focus and crystal thickness and that the fringes change in terms of their detail and thickness and shift relative to the structure if the crystal is tilted out of perfect orientation ( $c$ axis perpendicular to the electron beam). Even if fringe images cannot be interpreted as specific layers in the structure, however, the periodicities shown by the fringes reveal the periodicities in the real crystal and the combined thickness of the fringes correspond to the combined thickness of the actual layers (Guthrie and Veblen, 1989, 1990). In the present study, the majority of the measured fringes correspond to superstructures containing more than one individual layer (see Table 3) and thus are not affected by the problem of variation of the thickness of individual layers. For measurements corresponding to individual layers, only very few fringes found with $7-10 \AA$ could be affected by this problem and their small number precluded any significant effect on the quantification of layers.

All clay layers showed the typical wavy shape except in the two most kaolinitic samples (RS49 and CWP-73; Table 1), where some particles were straight (Figure 4). Crystal boundaries were ill-defined and layer terminations within crystals were not aligned, also with the exception of some particles in samples RS49 and CWP73. Such a general texture is typical of lattice-fringe images of smectite (e.g. figure 4 of Nieto et al., 1996).

Measurement of the distance between lattice fringes (from center to center of the dark fringes) yielded a wide range of values, from 7 to $36 \AA$, although the $7-10 \AA$ 
Table 3. Layer sequences and possible ranges of thickness of each series, used for the quantification of layer types in the HRTEM images.

\begin{tabular}{lcccccc}
\hline Layer series & SS & SKSS & SSK & SKS & SK & SKKS \\
Thickness $(\AA)$ & $9.5-15$ & $27.5-38$ & $18-23$ & $17.5-23$ & $8-9.7$ & $24.5-30$ \\
\hline Layer series & SKK & SKK $^{\dagger}$ & SKKKS & SKKK & KK & KKK \\
Thickness $(\AA)$ & $15-17.5$ & $11.5-13.5$ & $31.5-37$ & $23.5-29$ & $7-7.8$ & $14-14.8$ \\
\hline
\end{tabular}

${ }^{\dagger}$ Isolated sequence, where the two K layers are not resolved; see text.

values were very poorly represented and the great majority of values was in the range 11-20 $\mathrm{\AA}$. The very few $\sim 7 \AA$ fringes found are incompatible with the composition of the K-S samples and were interpreted as arising from a lack of image resolution, so that the individual $\sim 7 \AA$ layers could not be resolved from adjacent smectite or kaolinite layers. The result would be that the lattice fringes would correspond to superstructures containing more than one layer per fringe. Even smectite layers are frequently not resolved and they appear as superlattice fringes. The lack of resolution is due to structural damage, incorrect focus, different thickness, or minor misorientation of the crystal. The inset in Figure $4 \mathrm{~b}$ is from sample RS49 and shows two examples of features possibly related to kaolinite layers. The arrow indicates where two smectite layers merge, apparently, into one. This feature can be interpreted as two smectite layers having a transition to an SK layer pair that becomes unresolved due to the narrower layer distance. Amouric and Olives (1998) captured several images in which similar lateral transi- tions from smectite to kaolinite were resolved. The lines marking lattice fringes in the inset of Figure $4 \mathrm{~b}$ show a $13 \AA$ (smectite) and a $9 \AA$ distance. The latter is only barely visible due to the low contrast and should correspond to an SK layer pair (distance from the center of an $\mathrm{S}$ layer to a $\mathrm{K}$ layer).

In order to quantify the layer proportions in the samples, the following model of possible K-S layer sequences was generated which contains several assumptions. Possible layer sequences with both types of layers always have smectite layers at one or two of the crystal ends. For example, SKK sequences exist but not KSK sequences because the crystals are more likely to break at smectite interlayers than at kaolinite ones. In accordance with the transformation model of Dudek et al. (2006), the assumption is made here that kaolinite layers at the end of crystals had the tetrahedral sheet (rather than the octahedral sheet) on the external side. The distance between smectitic and kaolinitic layers is different depending on the orientation of the sequence, due to the non-centered character of the kaolinitic layer.
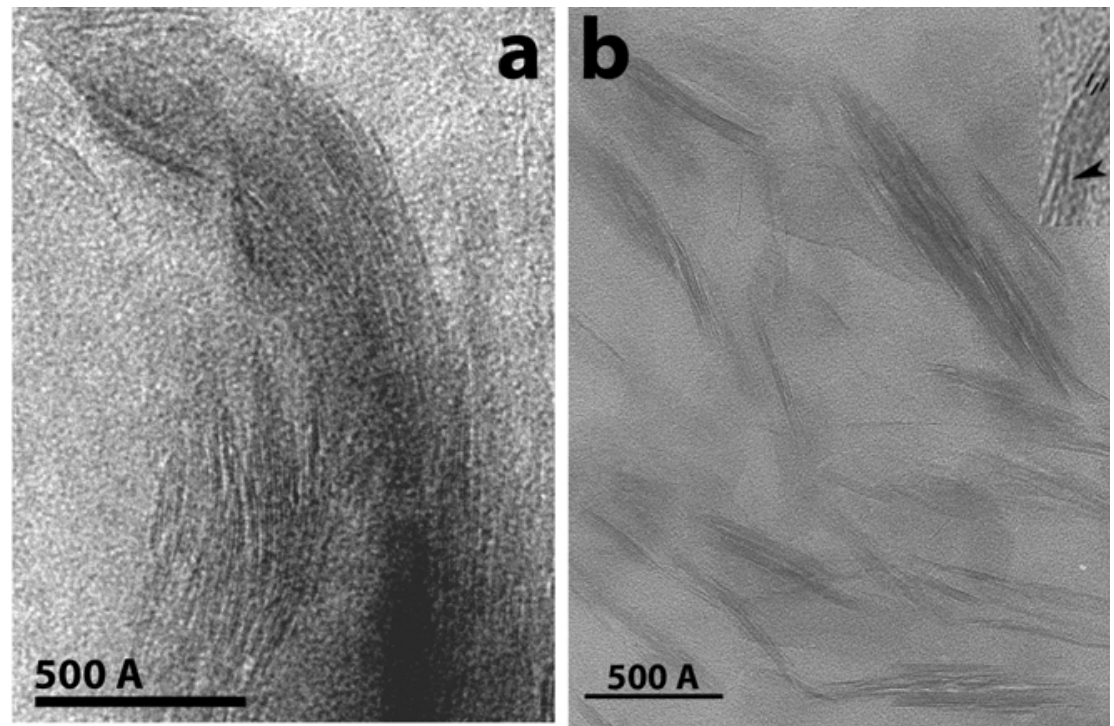

Figure 4. HRTEM images of samples TR-121 (a) and RS49 (b), showing typical particle shapes and areas where lattice fringes can be observed. The inset in (b) is also from sample RS49. It displays (arrow) two smectite layers apparently merging into one, interpreted as the transition from SS to SK where the kaolinite layer is unresolved. The three lines mark one clear lattice fringe of $13 \AA$ (SS pair) and another, with low contrast, of $9 \AA$ (SK pair). 
The distance TOT-OT (in this order; collapsed interlayer space) is $8 \AA$, while the distance $O T-T O T$ (smectitic interlayer) is $9.5 \AA$. In the latter example, the $O T$ layer is not at the end of the crystal but in the midst of other preceding layers, omitted for the sake of simplicity. Smectite was considered to have interlayer distances in the range 9.8-15 $\AA$, representing collapsed layers and those hydrated with up to two water layers. The entire range is possible in the vacuum of the microscope where the resin-embedding procedure may preserve the smectite expansion state totally or partially (Ahn and Peacor, 1980; Środoń et al., 1990). Two consecutive kaolinite layers can have a thickness of 7-7.8 $\AA$, to accommodate the possibility that the complex transformation mechanism may generate kaolinite layers which are partially expanded. In fact, modeling of the XRD patterns of oriented mounts frequently produced a kaolinite layer thickness of $7.4 \AA$ (Dudek et al., 2006).

With these assumptions, the group of layer sequences and possible range of thickness of these structures (or superstructures) was determined (Table 3 ). One layer is defined by two symbols, so that, for example, SK is one layer, SSK two layers, etc. Two SKK series were found (Table 3); the first, with a greater thickness range, corresponds to this sequence within a larger series; the second corresponds to the isolated sequence. In such a case, the two kaolinite layers probably become unresolved and appear as a single fringe, where the center is located in the actual interlayer space between them. The thickness of the series then appears smaller.

The number of fringes of different thickness was measured and then assigned to the possible sequences in Table 3 using the following criteria. If the thickness can be assigned to only one layer sequence, the corresponding probability is 1 . If several different assignments are possible, each is given a fraction of probability $(\mathrm{p}<1)$. The probability was weighted considering the actual nature of the sample; i.e. in smectite-rich samples (according to XRD), series with more smectite layers were favored, whereas in kaolinite-rich samples, kaolinite-rich series were given a greater probability. This probability weighting was distributed so that the ratio of favored to less favored sequences is $0.75 / 0.25$. For intermediate compositions, all possible series were given the same probability. The total sum of probabilities for each case is 1 . The results of the procedure described are shown in the last column of Table 1.

\section{DISCUSSION}

\section{Transformation from smectite to kaolinite}

The chemical data presented offer new information as they refer to individual particles rather than to the average composition of the K-S specimens, where significant information about chemical differences between individual particles is lost. The TEM study has confirmed that the material is quite pure K-S. The AEM analyses produced results perfectly compatible with the global compositions of the samples (Figure 3), though this composition is an average of a wide chemical range as shown by AEM results (Table 2). Such a chemical range is mainly the consequence of different degrees of kaolinization, indicated by the fact that differences among particles within samples are consistent with different proportions of smectite and kaolinite. Where the range of composition is wide enough, the chemical tendency is clearly from smectitic to kaolinitic compositions (Figure 1). In samples with a narrower range of compositions, the direction of the chemical changes (regression line in Figure 1) is not so clearly defined, due to analytical uncertainty linked to the relatively small $\mathrm{Mg}$ concentration, but the overall tendency is also toward a kaolinitic composition. The compositional heterogeneity of the particles within individual samples is also demonstrated by the highly variable lattice-fringe thicknesses measured using HRTEM, all of them interpretable as different combinations of individual layers of smectite and kaolinite (Table 3). The average of all these layer combinations defines the overall proportion of kaolinite and smectite in each sample (Table 1). The differences in latticefringe spacing are present even within individual particles (black arrow in Figure 4b).

The original material is smectite with a range of composition typical of this group of minerals (Table 2). The analyses of the less kaolinized particles produce formulae interpretable as smectite with an intermediate composition between montmorillonite and $\mathrm{Fe}$-containing beidellite, which have been widely described in nature (Güven, 1988; Drief and Nieto, 2000). The transformation of the smectite particles into kaolinite proceeds through partial destruction of one of the tetrahedral sheets according to the previously described model (Dudek et al., 2006). The different particles and the different parts of a single particle are affected by different degrees of transformation, which produces variable chemical compositions and lattice-fringe spacing. The overall material is, therefore, not an interstratified phyllosilicate with an homogeneous sequence of layers; instead, it is a complex intermediate material composed of highly reactive particles, heterogeneous in structure and composition.

Individual particles maintain a smectitic texture all along the transformation sequence (Figures 2, 4a) and only at the most evolved state of transformation do some particles display the characteristic hexagonal kaolinitic morphology (Figures 2, 4b). This morphological change could be produced because, at the point where most of the volume of a crystal has reached a kaolinitic $T O$ structure, new kaolinite cells may grow at the crystal edges, following the PBC (periodic bond chain) directions of kaolinite, and produce the platy hexagonal morphology. 


\section{Chemical evolution of the octahedral sheet with kaolinization}

The plot of $\mathrm{Si} / \mathrm{Al}$ ratios $v s . \% \mathrm{~K}$ (TG) (Figure 3) shows that chemical changes, and particularly chemical changes in the octahedral sheet, are concentrated in the intermediate values of $\% \mathrm{~K}$, as should be expected given that the crystalline structure is most unstable in this range of composition. The point is proven further by plotting the position of the 060 XRD peak vs. \%K (TG; Figure 5). The values of the 060 XRD peaks are from Dudek et al. (2006) and are a proxy for $\mathrm{Fe}$ and $\mathrm{Mg}$ content in the octahedral sheet because their ionic radii are larger than that of $\mathrm{Al}$ and thus their presence causes a larger $b$ dimension of the crystal lattice. Data points were used for all of the samples studied by Dudek et al. (2006). The position of the 060 peak for kaolinite is that from Bailey (1980).

The shape of the trend (Figure 5) is the same as that in Figure $3 \mathrm{~b}$. The variation of the $\mathrm{Si} / \mathrm{Al}$ ratio (Figure 3), however, has two sources, the loss of tetrahedral $\mathrm{Si}$ and the increase of octahedral $\mathrm{Al}$ (at the expense of $\mathrm{Mg}$ and $\mathrm{Fe}$ ), and thus the real shape of the curve should be more complex than that represented, which can be considered as an approximation. For example, it is evident that the $\mathrm{Si} / \mathrm{Al}$ rate should decrease more steeply in the first part of the curve (where it appears to remain almost constant) as tetrahedra are being lost. The position of the 060 peak (Figure 5), on the contrary, depends only on the $\mathrm{Mg}$ and $\mathrm{Fe}$ content in the octahedral sheet. For this reason, this curve is a more accurate representation of the changes in the octahedral sheet. This plot is good proof that the chemical changes in the octahedral sheet are concentrated in the intermediate range of K-S composition, due

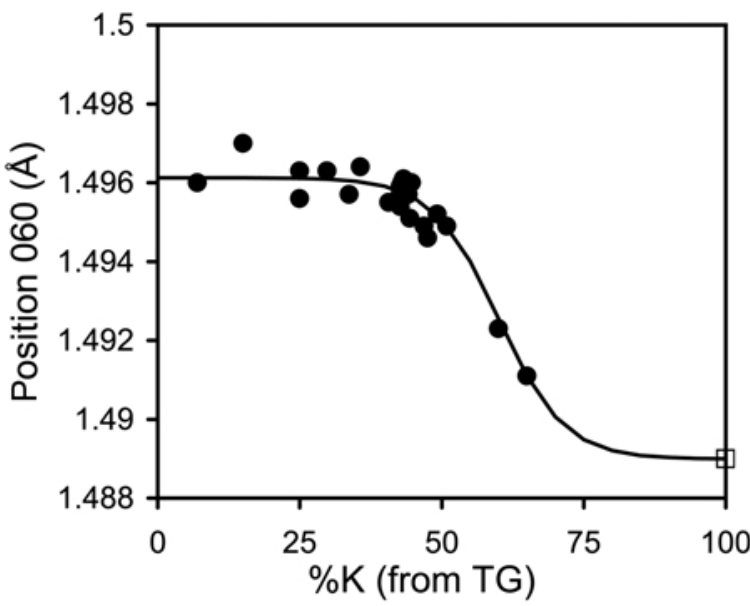

Figure 5. Position of the XRD 060 peak in K-S samples, as a proxy for the octahedral composition, vs. \% kaolinite, derived from TG. The $d$ value for kaolinite (square) is from Bailey (1980). The curve is a best-fit of all data points. The plot indicates that octahedral composition changes mainly in the $40-75 \% \mathrm{~K}$ region. to the unstable structure generated. The first part of the curve is well defined by the many data points, while this is not the case in the second part, especially above $\sim 70 \% \mathrm{~K}$. The curve, assumed to be symmetric, indicates that, in the range $70-100 \% \mathrm{~K}, \mathrm{Al}$ for $(\mathrm{Mg}+\mathrm{Fe})$ substitution proceeds ahead of the removal of tetrahedra. This is the case for $\mathrm{Mg}$ but not for Fe. Dudek et al. (2006) and Cuadros and Dudek (2006) showed with chemical and IR data, respectively, that Fe loss with kaolinization is much slower than $\mathrm{Mg}$ loss and it does not follow a defined trend. The results in Figure 5 are thus controlled by $\mathrm{Mg}$ loss. The real curve in Figure 5 should probably have slightly larger $d$ values in the $70-100 \% \mathrm{~K}$ stretch.

\section{Comparison of $\% \mathrm{~K}$ values from XRD, TG, and HRTEM}

The similarity of \%K (HRTEM) and \%K (TG) values (Table 1) is striking. The corresponding results from XRD are also similar for samples near $50 \% \mathrm{~K}$ but differ in the small and large kaolinite-content ranges because $\% \mathrm{~K}$ values from XRD and TG coincide in the range $40-50 \%$. The results from HRTEM layer-type quantification are to be considered with caution because of the assumptions involved in the analysis. In any case, these data are in better agreement with the TG-derived $\% \mathrm{~K}$ data than with those from XRD which is interesting as TG data are not directly correlated to layer thickness. In fact, it could be expected that the correlation between XRD and HRTEM would be better, as both measure distances between layers.

The explanation for this point could be that XRD analyzes the entire surface of layers within crystals, whereas only the edge of the crystals (in a plane parallel to the $c$ axis) is visible in HRTEM. The formation of kaolinite-like patches at the edges of crystals could result in immediate collapse to $\sim 7 \AA$ of the layers in this region because the layers are more flexible here, lacking the rigidity introduced by bonding to further atoms (armoring effect). Observations at the edge may, therefore, produce a good approximation to the real extent of kaolinite-like domain formation. Kaolinite-like domains well within crystals need to grow much more to produce layer collapse. The agreement between TG and HRTEM data also requires that the latter provides an accurate description of kaolinization at the surface of K-S crystals. In the kaolinization model of Dudek et al. (2006), \%K (XRD) becomes greater than \%K (TG) above $50 \% \mathrm{~K}$ because smectite layers at the surface of crystals are the last to lose their tetrahedral sheet and XRD misses a large part of this information due to imperfect alignment between crystals. Consequently, XRD gives more weight to the contribution of layers within crystals and overestimates the proportion of kaolinite. According to this interpretation and the data in Table 1, HRTEM characterizes correctly the nature of layers at the surfaces of crystals, probably because it only observes the edges of the crystals. When two 
crystals come into contact, HRTEM observation views them as a single layer sequence in a specific area of the contact even if the alignment of the crystals is not perfectly parallel, meaning that the outer layers in crystals are much more likely to be observed and characterized than with XRD analysis. The overall proportion of layers in K-S determined by HRTEM will, therefore, be more accurate because it takes into account the transformation in small areas of the outer layers in the crystals as well.

\section{ACKNOWLEDGMENTS}

Two of the samples were kindly supplied by J. Środoń and S. Hillier. The authors thank M.M. Abad and C. Hernández for technical support with the sample preparation and analysis. They also acknowledge financial support from the Royal Society-NATO (grant 15144/02B/TB), EPSRC (grant GR/S59772/01), the Marie Curie Fellowship Program (contract MEIF-CT-2003-501678), and the Spanish Ministry of Education and Science (Research Project CGL2007-66744). P. Ryan and S. Guggenheim are thanked for their insightful criticism and comments.

\section{REFERENCES}

Amouric, M. and Olives J. (1998) Transformation mechanisms and interstratification in conversion of smectite to kaolinite: an HRTEM study. Clays and Clay Minerals, 46, 521-527.

Ahn, J. and Peacor, D. (1989) Illite/smectite from Gulf Coast shales: A reappraisal of transmission electron microscope images. Clays and Clay Minerals, 37, 542-546.

Bailey, S.W. (1980) Structures of layer silicates. Pp. 2-124 in: Crystal Structures of Clay Minerals and their X-ray Identification (G.W. Brindley and G. Brown, editors). Monograph 5, Mineralogical Society, London.

Cliff, G. and Lorimer, G.W. (1975) The quantitative analysis of thin specimens. Journal of Microscopy, 103, 203-207.

Cuadros, J. and Dudek, T. (2006) FTIR investigation of the evolution of the octahedral sheet of kaolinite-smectite with progressive kaolinization. Clays and Clay Minerals, 54, $\underline{1-11 .}$

Cuadros, J. and Wing-Dudek, T. (2007) MAS NMR investigation of kaolinite-smectite structure using ${ }^{6} \mathrm{Li}$ and ${ }^{29} \mathrm{Si}$ with Mn exchange. Clay Minerals, 42, 181-186.

Drief, A., and Nieto, F. (2000) Chemical composition of smectites formed in clastic sediments. Implications for the smectite-illite transformation. Clay Minerals, 35, 665-678.
Dudek, T., Cuadros, J., and Fiore, S. (2006) Interstratified kaolinite-smectite: Nature of the layers and mechanism of smectite kaolinization. American Mineralogist, 91 , $159-170$

Dudek, T., Cuadros, J., and Huertas, J. (2007) Structure of mixed-layer kaolinite-smectite and smectite-to-kaolinite transformation mechanism from synthesis experiments. American Mineralogist, 92, 179-192.

Elsass, F., Beaumont, A., Pernes, M., Jaunet, A-M., and Tessier, D. (1998) Changes in layer organization of Na- and Ca-exchanged smectite materials during solvent exchanges for embedment in resin. The Canadian Mineralogist, 36 , $1475-1483$.

Guthrie, G. and Veblen, D. (1989) High-resolution transmission electron microscopy of mixed-layer illite/smectite: Computer simulations. Clays and Clay Minerals, 37, 1-11.

Guthrie, G. and Veblen, D. (1990) Interpreting one-dimensional high-resolution transmission electron micrographs of sheet silicates by computer simulation. American Mineralogist, 75, 276-288.

Güven, N. (19) $\overline{88}$ Smectite. Pp. 497-559 in: Hydrous Phyllosilicates (S.W. Bailey, editor). Reviews in Mineralogy, 19. Mineralogical Society of America, Washington DC, USA.

Nieto, F., Ortega-Huertas, M., Peacor, D., and Arostegui, J. (1996) Evolution of illite/smectite from early diagenesis through incipient metamorphism in sediments of the Basque-Cantabrian Basin. Clays and Clay Minerals, 44, 304-323.

Ryan, P.C. and Huertas, F.J. (2009) The temporal evolution of pedogenic $\mathrm{Fe}$-smectite to $\mathrm{Fe}$-kaolin via interstratified kaolin-smectite in a moist tropical soil chronosequence. Geoderma, 151, 1-15.

Spurr, A.R. (1969) A low viscosity epoxy resin embedding medium for electron microscopy. Journal of Ultrastructural Research, 26, 31-43.

Środoń, J., Andreoli, C., Elsass, F., and Robert, M. (1990) Direct high-resolution transmission electron microscopic measurements of expandability of mixed-layer illite/smectite in bentonite rock. Clays and Clay Minerals, 38, $373-379$

Tessier, D. (1984) Etude experimentale de l'organisation des materiaux argileux. PhD thesis, Univ. Paris VII, Paris.

Van Der Pluijm, B.A., Lee, J.H., and Peacor, D.R. (1988) Analytical electron microscopy and the problem of potassium diffusion. Clays and Clay Minerals, 36, 498-504.

(Received 28 April 2009; revised 23 July 2009; Ms. 314; A.E. S. Petit) 